\title{
COMparison of Load Restriction Timings DETERMINED Using FHWA Guidelines AND Frost Tubes
}

\author{
By Nazli Yesiller, Craig H. Benson, and Peter J. Bosscher
}

\begin{abstract}
Arstract: The Federal Highway Administration (FHwA) method and frost-tube measurements are used in Wisconsin to determine the timing and duration of spring load restrictions. In both methods, depth of freeze or thaw is used to determine when to apply load restrictions and to determine their duration. Average daily air temperatures are used in the FHwA method to predict the start and end of freeze and/or thaw. Frost tubes are used to directly determine depth of freeze and/or thaw. An analysis is conducted to compare these two methods using air-temperature data (for the FHwA method) and frost-tube data obtained in Wisconsin. The analysis shows that differences exist between predicted (FHwA method) and measured (frost tubes) freeze and thaw conditions. The FHwA method is early (unconservative) in predicting the start of freeze and late (unconservative) in predicting the start of thaw. However, the method is late (conservative) when used to predict the end of thaw. A case history is also presented to compare the two methods.
\end{abstract}

\section{INTRODUCTION}

Secondary routes, which constitute a significant number of highways, are typically constructed using flexible pavements. In frost-susceptible areas, these flexible pavements experience seasonal variations in strength. Pavements accumulate extra strength in late fall as soils underneath the pavements freeze. In some areas, overload is allowed during frozen periods. The strength of the pavement decreases significantly during the spring thaw due to increases in moisture content in the soil resulting from undrained conditions (Rutherford and Mahoney 1986). Consequently, load restrictions are applied during the thaw-weakening period to prevent structural damage to the pavement (Martinelli 1977; Mahoney et al. 1985; Rutherford and Mahoney 1986; McBane and Hanek 1986; Rwebangira et al. 1987; Barcomb 1989).

The timing and duration of highway load restrictions have a significant effect on commercial and noncommercial traffic. Load restrictions affect the accessibility of roads for many users, including trucks and buses. Overloading during frozen conditions permits the trucking industry to use more cost-effective routes. Thus, accurate timing of load restrictions is necessary to ensure maximum access to the road network while minimizing structural damage (Rutherford and Mahoney 1986).

Two common methods used in Wisconsin for determining the timing and duration of load restrictions are the Federal Highway Administration (FHwA) method and frost-tube measurements. In the FHwA method, air temperatures are used to predict the onset and duration of thaw weakening. The FHwA method can also be used to predict the start of the freezing season, although 
it was not intended for this purpose. Frost tubes are used to directly determine the depth of freeze or thaw, and thus the start of freeze or thaw and the end of weak conditions. In this paper, an analysis is described that compares these two methods using air-temperature data (for the FHwA method) and frosttube data obtained in Wisconsin.

\section{METHODS}

\section{FHwA Method}

The FHwA method (Mahoney et al. 1987) for predicting the start of freeze, start of thaw, and end of thaw is easy to use, because only air temperatures are required to predict phase changes in the ground. The method is semiempirical and was developed using Goering and Zarling's (1985) two-dimensional finite-element heat-transfer model, which includes latent heat effects (Rutherford and Mahoney 1986). Thermal analyses were conducted to determine the depth of freezing under four different pavement sections representative of pavements susceptible to thaw weakening. The analyses included the effects of surface temperature variation, free and forced convection, and radiation.

Mahoney et al. (1987) obtained monthly average temperatures for 60 locations in frost-susceptible areas in the United States that had made annual air temperatures between $4.4^{\circ} \mathrm{C}$ and $10^{\circ} \mathrm{C}$. The temperature data were combined into seven surface temperature-time relationships described by sinusoidal temperature functions. These relationships were then used in the thermal analysis. Some thermal parameters (e.g., geothermal gradient, short-wave radiation heat flux, and wind speed) for the soil and pavement were estimated from data reported in literature, while other parameters (e.g., long-wave radiation heat flux, thermal conductivity, and convection coefficient) were calculated using estimation equations (Rutherford and Mahoney 1986).

Rutherford and Mahoney (1986) state that thaw reaching the bottom of the
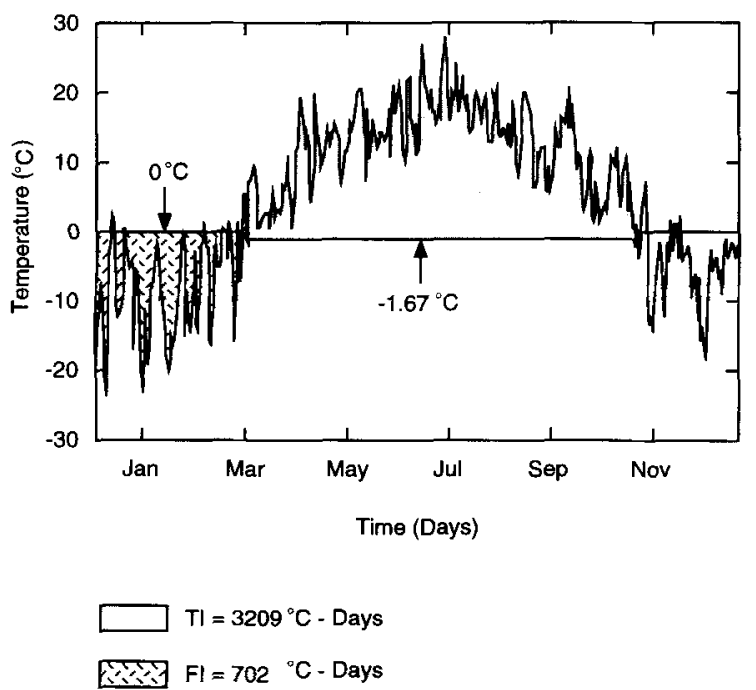

FIG. 1. Average Daily Temperatures for 1986 from Weather Station at Newald, Wisconsin 
base course indicates the onset of weak conditions, and that complete thaw corresponds to the end of weak conditions. They used results of the thermal analyses to correlate depth of thaw to air temperatures and then developed criteria for predicting the start and duration of thaw weakening that are based on the freezing and thawing indices (FI and $T I$, respectively). $F I$ is the area bounded by a temperature-time plot for temperatures below $0^{\circ} \mathrm{C}$ (Fig. 1)

$$
F I=\sum_{i=1}^{N}\left(0-T_{\text {iavg }}\right) \Delta t
$$

where $N=$ total number of time intervals for which average daily temperatures are below $0^{\circ} \mathrm{C} ; T_{\text {iavg }}=$ average temperature for time interval $i$ in ${ }^{\circ} \mathrm{C}$; and $\Delta t=$ time difference between consecutive points (period) in the temperaturetime plot. A period of 1 day is used. TI is defined as the area bounded by a temperature-time plot for temperatures above $-1.67^{\circ} \mathrm{C}$ (assumed freezing point for soil)

$$
T I=\sum_{i=1}^{N}\left[T_{\text {iavg }}-(-1.67)\right] \Delta t
$$

According to the FHwA method, the freezing season starts when the average daily temperature becomes less than or equal to $0^{\circ} \mathrm{C}$ "for several days" (Mahoney et al. 1987). The spring thawing season (late February to April) starts when the average daily temperature becomes more than $-1.67^{\circ} \mathrm{C}$ "for several days." It is suggested that a temperature of $-0.56^{\circ} \mathrm{C}$ be used for midwinter thawing (Rutherford and Mahoney 1986). The number of consecutive days required for the start of a freezing or thawing season is not specified in the FHwA method.

$T I$ is used to determine when to apply load restrictions after the thawing season begins. Timing of the restrictions is divided into two levels: the "should" level and the "must" level. The "should" level corresponds to thaw reaching the bottom of the base course (Fig. 2). For thin pavement sections (Fig. 2), the "should" level load restriction is applied when the

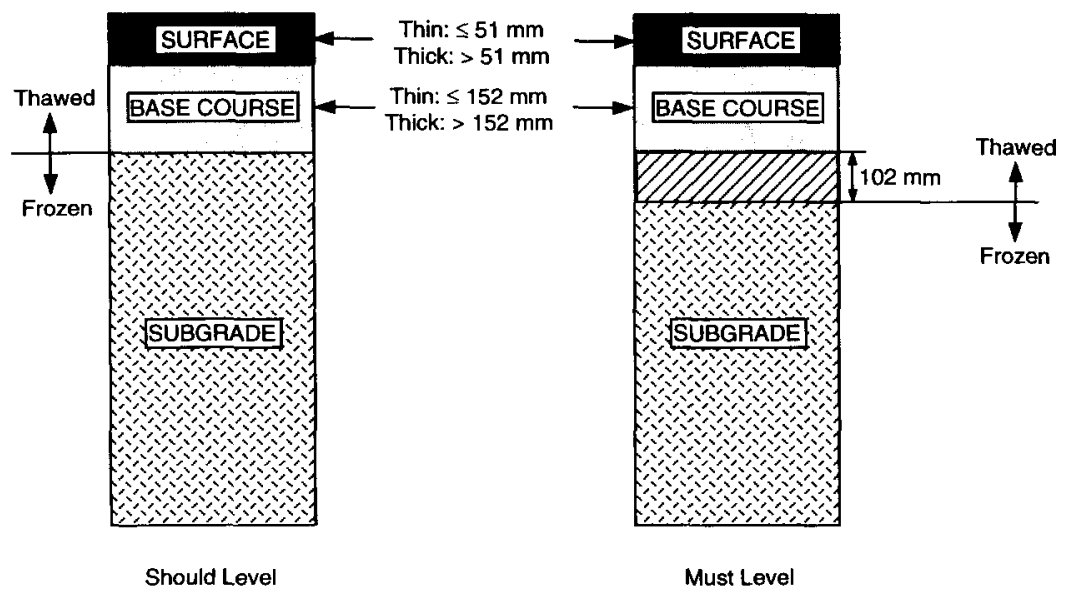

FIG. 2. FHwA Timing of Load Restrictions as It Relates to Frozen Road Geometry 
thawing index exceeds $5.6^{\circ} \mathrm{C}$-days, whereas for thick pavement sections it is applied (Fig. 2) when the thawing index exceeds $13.9^{\circ} \mathrm{C}$-days. The "must" level corresponds to thawing $102 \mathrm{~mm}$ below the bottom of the base course (Fig. 2). The "must" level load restriction is applied to thin pavement sections when the thawing index exceeds $22.2^{\circ} \mathrm{C}$-days, whereas for thick pavement it is applied when the thawing index exceeds $27.8^{\circ} \mathrm{C}$-days.

Results of the thermal analysis were also used to develop a criterion to predict the end of thaw and thus the end of critical conditions. Relationships between freezing conditions and duration of thaw were investigated (Rutherford and Mahoney 1986). A regression analysis was conducted for each pavement section to relate $T I$ corresponding to complete thaw and FI (Rutherford and Mahoney 1986; Mahoney et al. 1987)

$$
T I=4.154+0.259 F I
$$

Another approximate relationship is also presented in the FHwA method

$$
T I=0.3 F I
$$

The temperature data used to develop these relationships cover freezing indices between $204^{\circ} \mathrm{C}$-days and $1,093^{\circ} \mathrm{C}$-days. Rutherford and Mahoney (1986) report that these regression equations predict the relationship between thawing index and freezing index well for the fine-grained soils in their database, but poorer correlations exist when the subgrade soils are coarsegrained.

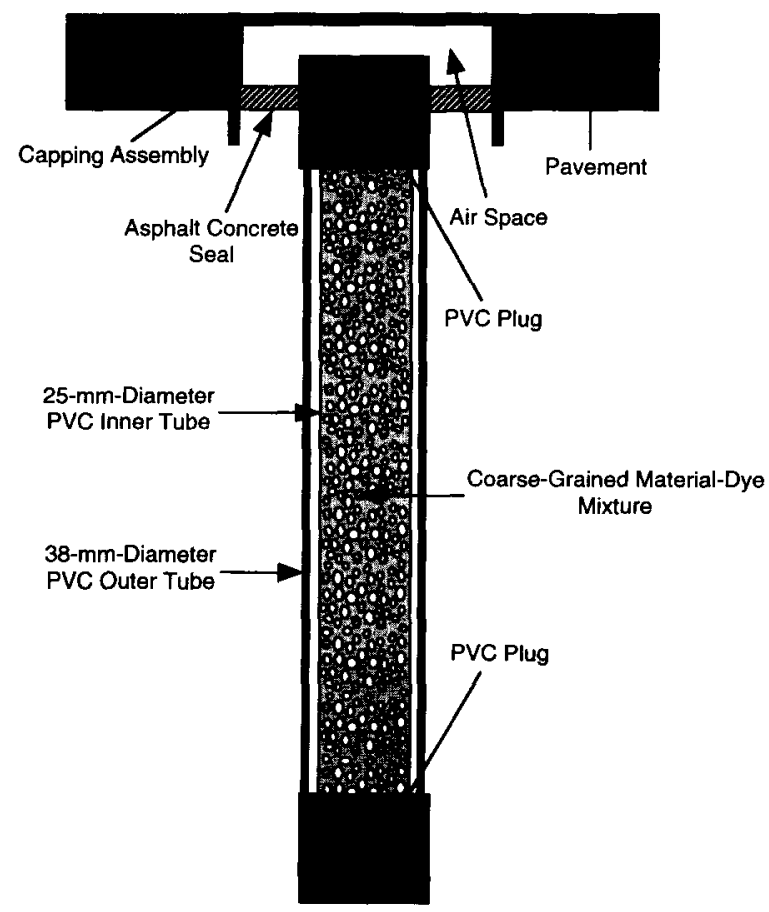

FIG. 3. Cross Section of Wisconsin Frost Tube (after Martinelli 1977) 


\section{Frost Tubes}

Frost tubes are used throughout frost-susceptible areas in the United States to monitor the depth of freeze and/or thaw in the soil. The tubes are installed under pavement sections that are susceptible to thaw weakening.

The frost tubes in Wisconsin consist of two concentric plastic pipes (Martinelli 1977). A 38-mm-diameter outer pipe is permanently installed to act as a protective sheath for the inner pipe (Fig. 3). The 25-mm-diameter clear inner pipe is the frost tube, which is removable. A small air gap exists between the cap and the surface of the tube. The air in this gap does insulate the tube slightly, but there is sufficient thermal mass surrounding the tube to make this insulation effect negligible.

The clear inner tube is filled with a mixture of coarse-grained material and colored dye. The dye changes color when it freezes and returns to its original color when it thaws. The color changes in the dye correlate well with the phase changes of the porewater in the surrounding soils (Martinelli 1977), although a detailed evaluation of the precision of frost tube measurements has not yet been conducted in Wisconsin.

Frost-tube data are collected by removing the inner tube and measuring the depth of frozen and/or thawed dye in the tube (Fig. 4). The measurements are conducted at intervals of several days. Consequently, in most cases, it is not possible to capture the exact day when freezing or thawing begins, or when thaw is complete. Therefore, in this study the start or end of a phase change is defined as an interval rather than a specific day (Fig. 4).

Data from District 7, Forest County, Frost Tube FO4, 1978-1979 Winter

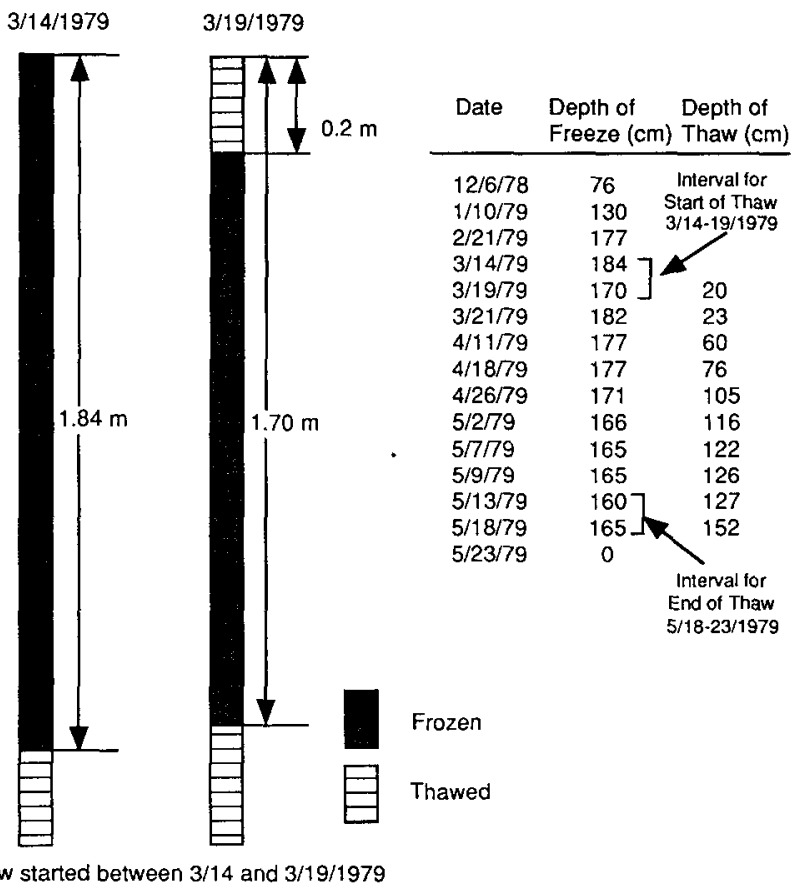

FIG. 4. Example of Frost-Depth Data from Frost Tube 


\section{RESULTS}

Air temperatures from four districts in Wisconsin were used to predict the start of freeze, start of thaw, and end of thaw (complete thaw) using the FHwA method. The predictions were then compared with the start of freeze, start of thaw, and end of thaw (complete thaw) determined using the frosttube data. The frost depths measured with the frost tubes were assumed to represent the actual phase changes in the soil, as reported by Martinelli (1977).

Average daily air temperatures were obtained from the Wisconsin State Climatologist's Office. A map that shows locations of the weather stations and frost tubes is shown in Fig. 5. Daily high and low temperatures from November through May were obtained using data from the weather stations. Average daily temperatures were calculated as the arithmetic mean of the daily high and low temperatures. Start of freeze, start of thaw, and end of thaw were determined using procedures described in the previous section.

Properties and thicknesses of the pavement sections were obtained when available from boring logs near the frost tubes (Fig. 6). These logs indicate that the thicknesses of the surface and subbase sections for all of the sites are more than 51 and $152 \mathrm{~mm}$, respectively. Therefore, the FHwA analyses were conducted assuming "thick" pavement sections. A surface thickness of

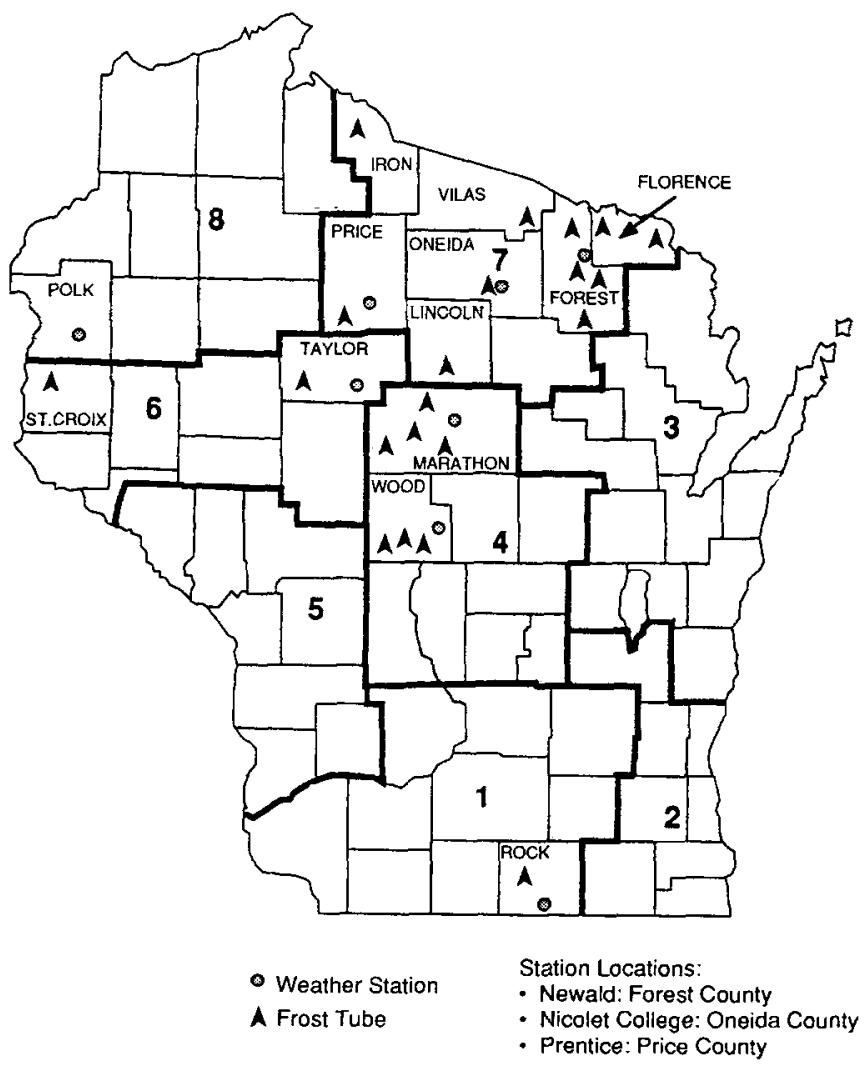

FIG. 5. Locations of Weather Stations and Frost Tubes 


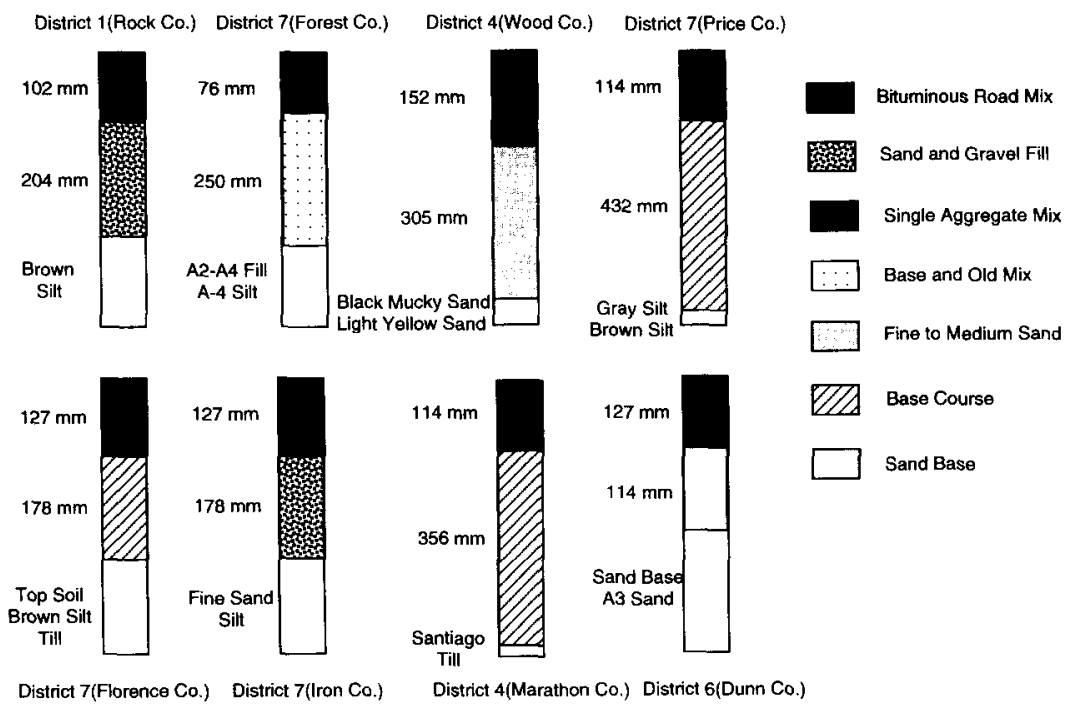

FIG. 6. Cross Sections of Pavements Used in Study

$102 \mathrm{~mm}$ and a subbase thickness of $152 \mathrm{~mm}$ were assumed for locations where thicknesses of pavement sections were not known.

Early Freeze, Early Thaw, and Late Freeze

An example of an analysis conducted using the FHwA method is presented in Table 1. Air temperatures for the winter of 1982-1983 were obtained from the Newald Weather Station located in District 7 (Fig. 5).

The freezing season started on December 4, 1982. Two freezing periods occurred in November, however, that could have been interpreted as the start of the freezing season (11/12/82 through $11 / 17 / 82$ and 11/22/82 through $11 / 30 / 82$, Table 1). These "early freeze" periods were followed by thawing; thus, they were not the true start of the actual freezing season (Table 1).

Thawing $102 \mathrm{~mm}$ below the bottom of the base course occurred on April $6,1983\left(T I=27.8^{\circ} \mathrm{C}\right.$-days $)$. However, two "early thaws" occurred earlier in $1983(2 / 13 / 82$ through $2 / 23 / 83$ and $2 / 27 / 82$ through $3 / 8 / 83$, Table 1$)$, which could have been interpreted as the start of the thaw season. These early thaw periods were followed by freezing and thus the early thaws were not the true start of thaw.

Finally, a "late freeze" occurred between April 15 and 19, 1983 (Table 1), after the start of thawing.

Consequently, when real-time data are analyzed, an "early freeze" can mistakenly be interpreted as the start of the freezing season. Similarly, an "early thaw" can mistakenly be interpreted as the start of the thawing season.

\section{Frost Tubes versus FHwA Method}

Frost tubes were installed in Wisconsin in the fall of 1973 and the fall of 1974. However, continuous measurements since 1973 have only been recorded in District 7. Data for the winter of 1976-77 obtained from a frost tube in District 7 are presented in Fig. 7. These data are characteristic of the type of data obtained from other frost tubes in Wisconsin. 
TABLE 1. Timing and Duration of Load Restrictions (Average Daily Temperatures from Newald, District 7, Winter 1982-83)

\begin{tabular}{|c|c|c|c|c|c|}
\hline $\begin{array}{c}\text { Date } \\
\text { (1) }\end{array}$ & $\begin{array}{c}\text { Average } \\
\text { temperature } \\
\left({ }^{\circ} \mathrm{C}\right) \\
(2)\end{array}$ & $\begin{array}{c}\text { 0-average } \\
\text { temperature } \\
\text { (3) }\end{array}$ & $\begin{array}{l}F I \\
(4)\end{array}$ & $\begin{array}{c}\text { Average } \\
\text { temperature } \\
(-1.67) \\
(5)\end{array}$ & $\begin{array}{l}T I \\
(6)\end{array}$ \\
\hline $11 / 1 / 82$ & 6.1 & -6.1 & & 7.8 & \\
\hline $11 / 2 / 82$ & 6.1 & -6.1 & & 7.8 & \\
\hline $11 / 3 / 82$ & 3.3 & -3.3 & & 5.0 & \\
\hline $11 / 4 / 82$ & -1.7 & 1.7 & & 0.0 & \\
\hline $11 / 5 / 82$ & -1.7 & 1.7 & & 0.0 & \\
\hline $11 / 6 / 82$ & -1.7 & 1.7 & & 0.0 & \\
\hline $11 / 7 / 82$ & 2.8 & -2.8 & & 4.4 & \\
\hline $11 / 8 / 82$ & 3.3 & -3.3 & & 5.0 & \\
\hline $11 / 9 / 82$ & 0.6 & -0.6 & & 2.2 & \\
\hline $11 / 10 / 82$ & 0.0 & 0.0 & & 1.7 & \\
\hline $11 / 11 / 82$ & 1.7 & -1.7 & & 3.3 & \\
\hline $11 / 12 / 82$ & -1.1 & 1.1 & $1.1^{2}$ & 0.6 & \\
\hline $11 / 13 / 82$ & -8.9 & 8.9 & 10.0 & -7.2 & \\
\hline $11 / 14 / 82$ & -6.7 & 6.7 & 16.7 & -5.0 & \\
\hline $11 / 15 / 82$ & -7.8 & 7.8 & 24.4 & -6.1 & \\
\hline $11 / 16 / 82$ & -4.4 & 4.4 & 28.9 & -2.8 & \\
\hline $11 / 17 / 82$ & -4.4 & 4.4 & 33.3 & -2.8 & \\
\hline $11 / 18 / 82$ & 0.6 & -0.6 & & 2.2 & \\
\hline $11 / 19 / 82$ & 3.9 & -3.9 & & 5.6 & \\
\hline $11 / 20 / 82$ & 11.1 & -11.1 & & 12.8 & \\
\hline $11 / 21 / 82$ & 4.4 & -4.4 & & 6.1 & \\
\hline $11 / 22 / 82$ & 0.0 & 0.0 & $0.0^{\circ}$ & 1.7 & \\
\hline $11 / 23 / 82$ & -3.3 & 3.3 & 3.3 & -1.7 & \\
\hline $11 / 24 / 82$ & -8.3 & 8.3 & 11.7 & -6.7 & \\
\hline $11 / 25 / 82$ & -5.6 & 5.6 & 17.2 & -3.9 & \\
\hline $11 / 26 / 82$ & -5.6 & 5.6 & 22.8 & -3.9 & \\
\hline $11 / 27 / 82$ & -10.0 & 10.0 & 32.8 & -8.3 & \\
\hline $11 / 28 / 82$ & -4.4 & 4.4 & 37.2 & -2.8 & \\
\hline $11 / 29 / 82$ & -3.3 & 3.3 & 40.6 & -1.7 & \\
\hline $11 / 30 / 82$ & -0.6 & 0.6 & 41.1 & 1.1 & \\
\hline $12 / 1 / 82$ & 2.8 & -2.8 & & 4.4 & \\
\hline $12 / 2 / 82$ & 9.4 & -9.4 & & 11.1 & \\
\hline $12 / 3 / 82$ & 8.3 & -8.3 & & 10.0 & \\
\hline $12 / 4 / 82$ & -0.6 & 0.6 & $0.6^{\mathrm{b}}$ & 1.1 & \\
\hline $12 / 5 / 82$ & -1.1 & 1.1 & 1.7 & 0.6 & \\
\hline $12 / 6 / 82$ & -3.3 & 3.3 & 5.0 & -1.7 & \\
\hline $12 / 7 / 82$ & -8.9 & 8.9 & 13.9 & -7.2 & \\
\hline $12 / 8 / 82$ & -15.0 & 15.0 & 28.9 & -13.3 & \\
\hline $12 / 9 / 82$ & -16.7 & 16.7 & 45.6 & -15.0 & \\
\hline $12 / 10 / 82$ & -8.9 & 8.9 & 54.4 & -7.2 & \\
\hline $12 / 11 / 82$ & -13.9 & 13.9 & 68.3 & -12.2 & \\
\hline $12 / 12 / 82$ & -13.9 & 13.9 & 82.2 & -12.2 & \\
\hline $12 / 13 / 82$ & -7.8 & 7.8 & 90.0 & -6.1 & \\
\hline $12 / 14 / 82$ & -4.4 & 4.4 & 94.4 & -2.8 & \\
\hline $12 / 15 / 82$ & -5.0 & 5.0 & 99.4 & -3.3 & \\
\hline $12 / 16 / 82$ & -6.7 & 6.7 & 106.1 & -5.0 & \\
\hline $12 / 17 / 82$ & -11.7 & 11.7 & 117.8 & -10.0 & \\
\hline $12 / 18 / 82$ & -1.7 & 1.7 & 119.4 & 0.0 & \\
\hline $12 / 19 / 82$ & -1.7 & 1.7 & 121.1 & 0.0 & \\
\hline $12 / 20 / 82$ & -5.6 & 5.6 & 126.7 & -3.9 & \\
\hline $12 / 21 / 82$ & -5.6 & 5.6 & 132.2 & -3.9 & \\
\hline
\end{tabular}


TABLE 1 (Continued)

\begin{tabular}{|c|c|c|c|c|c|}
\hline (1) & (2) & (3) & (4) & (5) & (6) \\
\hline $12 / 22 / 82$ & -7.2 & 7.2 & 139.4 & -5.6 & \\
\hline $12 / 23 / 82$ & -1.1 & 1.1 & 140.6 & 0.6 & \\
\hline $12 / 24 / 82$ & 0.6 & -0.6 & 140.0 & 2.2 & \\
\hline $12 / 25 / 82$ & 0.6 & -0.6 & 139.4 & 2.2 & \\
\hline $12 / 26 / 82$ & -2.2 & 2.2 & 141.7 & -0.6 & \\
\hline $12 / 27 / 82$ & -6.1 & 6.1 & 147.8 & -4.4 & \\
\hline $12 / 28 / 82$ & -3.9 & 3.9 & 151.7 & -2.2 & \\
\hline $12 / 29 / 82$ & -11.1 & 11.1 & 162.8 & -9.4 & \\
\hline $12 / 30 / 82$ & -13.9 & 13.9 & 176.7 & -12.2 & \\
\hline $12 / 31 / 82$ & -8.9 & 8.9 & 185.6 & -7.2 & \\
\hline $1 / 1 / 83$ & -5.0 & 5.0 & 190.6 & -3.3 & \\
\hline $1 / 2 / 83$ & -10.0 & 10.0 & 200.6 & -8.3 & \\
\hline $1 / 3 / 83$ & -11.7 & 11.7 & 212.2 & -10.0 & \\
\hline $1 / 4 / 83$ & -5.6 & 5.6 & 217.8 & -3.9 & \\
\hline $1 / 5 / 83$ & -3.3 & 3.3 & 221.1 & -1.7 & \\
\hline $1 / 6 / 83$ & -4.4 & 4.4 & 225.6 & -2.8 & \\
\hline $1 / 7 / 83$ & -4.4 & 4.4 & 230.0 & -2.8 & \\
\hline $1 / 8 / 83$ & -15.0 & 15.0 & 245.0 & -13.3 & \\
\hline $1 / 9 / 83$ & -2.8 & 2.8 & 247.8 & -1.1 & \\
\hline $1 / 10 / 83$ & -0.6 & 0.6 & 248.3 & 1.1 & \\
\hline $1 / 11 / 83$ & -4.4 & 4.4 & 252.8 & -2.8 & \\
\hline $1 / 12 / 83$ & -14.4 & 14.4 & 267.2 & -12.8 & \\
\hline $1 / 13 / 83$ & -8.3 & 8.3 & 275.6 & -6.7 & \\
\hline $1 / 14 / 83$ & -7.2 & 7.2 & 282.8 & -5.6 & \\
\hline $1 / 15 / 83$ & -10.0 & 10.0 & 292.8 & -8.3 & \\
\hline $1 / 16 / 83$ & -13.3 & 13.3 & 306.1 & -11.7 & \\
\hline $1 / 17 / 83$ & -13.9 & 13.9 & 320.0 & -12.2 & \\
\hline $1 / 18 / 83$ & -18.9 & 18.9 & 338.9 & -17.2 & \\
\hline $1 / 19 / 83$ & -17.2 & 17.2 & 356.1 & -15.6 & \\
\hline $1 / 20 / 83$ & -10.6 & 10.6 & 366.7 & -8.9 & \\
\hline $1 / 21 / 83$ & -8.9 & 8.9 & 375.6 & -7.2 & \\
\hline $1 / 22 / 83$ & -8.3 & 8.3 & 383.9 & -6.7 & \\
\hline $1 / 23 / 83$ & -1.1 & 1.1 & 385.0 & 0.6 & \\
\hline $1 / 24 / 83$ & -2.2 & 2.2 & 387.2 & -0.6 & \\
\hline $1 / 25 / 83$ & -8.9 & 8.9 & 396.1 & -7.2 & \\
\hline $1 / 26 / 83$ & -19.4 & 19.4 & 415.6 & -17.8 & \\
\hline $1 / 27 / 83$ & -21.1 & 21.1 & 436.7 & -19.4 & \\
\hline $1 / 28 / 83$ & -7.2 & 7.2 & 443.9 & -5.6 & \\
\hline $1 / 29 / 83$ & -1.1 & 1.1 & 445.0 & 0.6 & \\
\hline $1 / 30 / 83$ & -1.7 & 1.7 & 446.7 & 0.0 & \\
\hline $1 / 31 / 83$ & -5.6 & 5.6 & 452.2 & -3.9 & \\
\hline $2 / 1 / 83$ & -7.2 & 7.2 & 459.4 & -5.6 & \\
\hline $2 / 2 / 83$ & -5.6 & 5.6 & 465.0 & -3.9 & \\
\hline $2 / 3 / 83$ & -8.3 & 8.3 & 473.3 & -6.7 & \\
\hline $2 / 4 / 83$ & -10.0 & 10.0 & 483.3 & -8.3 & \\
\hline $2 / 5 / 83$ & -11.7 & 11.7 & 495.0 & -10.0 & \\
\hline $2 / 6 / 83$ & -8.9 & 8.9 & 503.9 & -7.2 & \\
\hline $2 / 7 / 83$ & -13.9 & 13.9 & 517.8 & -12.2 & \\
\hline $2 / 8 / 83$ & -13.9 & 13.9 & 531.7 & -12.2 & \\
\hline $2 / 9 / 83$ & -10.0 & 10.0 & 541.7 & -8.3 & \\
\hline $2 / 10 / 83$ & -7.8 & 7.8 & 549.4 & -6.1 & \\
\hline $2 / 11 / 83$ & -6.7 & 6.7 & 556.1 & -5.0 & \\
\hline $2 / 12 / 83$ & -3.3 & 3.3 & 559.4 & -1.7 & \\
\hline $2 / 13 / 83$ & 1.7 & -1.7 & 557.8 & 3.3 & $3.3^{c}$ \\
\hline $2 / 14 / 83$ & 2.2 & -2.2 & 555.6 & 3.9 & 7.2 \\
\hline $2 / 15 / 83$ & 1.1 & -1.1 & 554.4 & 2.8 & 10.0 \\
\hline
\end{tabular}


TABLE 1 (Continued)

\begin{tabular}{|c|c|c|c|c|c|}
\hline (1) & (2) & (3) & (4) & (5) & (6) \\
\hline $2 / 16 / 83$ & 0.6 & -0.6 & 553.9 & 2.2 & 12.2 \\
\hline $2 / 17 / 83$ & 2.8 & -2.8 & 551.1 & 4.4 & 16.7 \\
\hline $2 / 18 / 83$ & -1.1 & 1.1 & 552.2 & 0.6 & 17.2 \\
\hline $2 / 19 / 83$ & 0.6 & -0.6 & 551.7 & 2.2 & 19.5 \\
\hline $2 / 20 / 83$ & 3.3 & -3.3 & 548.3 & 5.0 & 24.5 \\
\hline $2 / 21 / 83$ & 1.7 & -1.7 & 546.7 & 3.3 & 27.8 \\
\hline $2 / 22 / 83$ & -0.6 & 0.6 & 547.2 & 1.1 & 28.9 \\
\hline $2 / 23 / 83$ & -0.6 & 0.6 & 547.8 & 1.1 & 30.0 \\
\hline $2 / 24 / 83$ & -4.4 & 4.4 & 552.2 & -2.8 & \\
\hline $2 / 25 / 83$ & -5.6 & 5.6 & 557.8 & -3.9 & \\
\hline $2 / 26 / 83$ & -6.7 & 6.7 & 564.4 & -5.0 & \\
\hline $2 / 27 / 83$ & 4.4 & -4.4 & 560.0 & 6.1 & $6.1^{c}$ \\
\hline $2 / 28 / 83$ & 0.6 & -0.6 & 559.4 & 2.2 & 8.3 \\
\hline $3 / 1 / 83$ & 1.1 & -1.1 & 558.3 & 2.8 & 11.1 \\
\hline $3 / 2 / 83$ & 2.8 & -2.8 & 555.6 & 4.4 & 15.6 \\
\hline $3 / 3 / 83$ & 0.0 & 0.0 & 555.6 & 1.7 & 17.2 \\
\hline $3 / 4 / 83$ & 2.2 & -2.2 & 553.3 & 3.9 & 21.1 \\
\hline $3 / 5 / 83$ & 3.3 & -3.3 & 550.0 & 5.0 & 26.1 \\
\hline $3 / 6 / 83$ & 4.4 & -4.4 & 545.6 & 6.1 & 32.2 \\
\hline $3 / 7 / 83$ & 6.1 & -6.1 & 539.4 & 7.8 & 40.0 \\
\hline $3 / 8 / 83$ & 3.3 & -3.3 & 536.1 & 5.0 & 45.0 \\
\hline $3 / 9 / 83$ & -2.8 & 2.8 & 538.9 & -1.1 & \\
\hline $3 / 10 / 83$ & -6.7 & 6.7 & 545.6 & -5.0 & \\
\hline $3 / 11 / 83$ & -2.8 & 2.8 & 548.3 & -1.1 & \\
\hline $3 / 12 / 83$ & -3.3 & 3.3 & 551.7 & -1.7 & \\
\hline $3 / 13 / 83$ & -1.7 & 1.7 & 553.3 & 0.0 & \\
\hline $3 / 14 / 83$ & 1.7 & -1.7 & 551.7 & 3.3 & \\
\hline $3 / 15 / 83$ & -2.2 & 2.2 & 553.9 & -0.6 & \\
\hline $3 / 16 / 83$ & 0.0 & 0.0 & 553.9 & 1.7 & \\
\hline $3 / 17 / 83$ & 0.6 & -0.6 & 553.3 & 2.2 & \\
\hline $3 / 18 / 83$ & 0.6 & -0.6 & 552.8 & 2.2 & \\
\hline $3 / 19 / 83$ & -3.3 & 3.3 & 556.1 & -1.7 & \\
\hline $3 / 20 / 83$ & -5.0 & 5.0 & 561.1 & -3.3 & \\
\hline $3 / 21 / 83$ & -7.8 & 7.8 & 568.9 & -6.1 & \\
\hline $3 / 22 / 83$ & -7.2 & 7.2 & 576.1 & -5.6 & \\
\hline $3 / 23 / 83$ & -11.7 & 11.7 & 587.8 & -10.0 & \\
\hline $3 / 24 / 83$ & -11.7 & 11.7 & 599.4 & -10.0 & \\
\hline $3 / 25 / 83$ & -7.8 & 7.8 & 607.2 & -6.1 & \\
\hline $3 / 26 / 83$ & -3.3 & 3.3 & 610.6 & -1.7 & \\
\hline $3 / 27 / 83$ & -0.6 & 0.6 & 611.1 & 1.1 & \\
\hline $3 / 28 / 83$ & -0.6 & 0.6 & 611.7 & 1.1 & \\
\hline $3 / 29 / 83$ & -5.6 & 5.6 & $617.2^{\mathrm{d}}$ & -3.9 & \\
\hline $3 / 30 / 83$ & -0.6 & 0.6 & & 1.1 & $1.1^{\circ}$ \\
\hline $3 / 31 / 83$ & 0.6 & -0.6 & & 2.2 & 3.3 \\
\hline $4 / 1 / 83$ & 3.9 & -3.9 & & 5.6 & 8.9 \\
\hline $4 / 2 / 83$ & 2.8 & -2.8 & & 4.4 & 13.3 \\
\hline $4 / 3 / 83$ & 1.7 & -1.7 & & 3.3 & $16.7^{t}$ \\
\hline $4 / 4 / 83$ & 0.6 & -0.6 & & 2.2 & 18.9 \\
\hline $4 / 5 / 83$ & 2.8 & -2.8 & & 4.4 & 23.4 \\
\hline $4 / 6 / 83$ & 2.8 & -2.8 & & 4.4 & $27.8^{8}$ \\
\hline $4 / 7 / 83$ & 1.7 & -1.7 & & 3.3 & 31.1 \\
\hline $4 / 8 / 83$ & 1.7 & -1.7 & & 3.3 & 34.5 \\
\hline 4/9/83 & 2.8 & -2.8 & & 4.4 & 38.9 \\
\hline $4 / 10 / 83$ & 1.7 & -1.7 & & 3.3 & 42.3 \\
\hline $4 / 11 / 83$ & 2.8 & -2.8 & & 4.4 & 46.7 \\
\hline $4 / 12 / 83$ & 3.3 & -3.3 & & 5.0 & 51.7 \\
\hline
\end{tabular}


TABLE 1 (Continued)

\begin{tabular}{c|r|r|r|r|r}
\hline$(1)$ & $(2)$ & $(3)$ & $(4)$ & \multicolumn{1}{c}{$(5)$} & $(6)$ \\
\hline $4 / 13 / 83$ & 3.3 & -3.3 & & 5.0 & 56.7 \\
$4 / 14 / 83$ & 2.8 & -2.8 & & 4.4 & 61.2 \\
$4 / 15 / 83$ & -2.8 & 2.8 & 2.8 & -1.1 & 60.1 \\
$4 / 16 / 83$ & -8.3 & 8.3 & 11.1 & -6.7 & 53.4 \\
$4 / 17 / 83$ & -6.7 & 6.7 & 17.8 & -5.0 & 48.4 \\
$4 / 18 / 83$ & -5.6 & 5.6 & 23.3 & -3.9 & 44.5 \\
$4 / 19 / 83$ & -2.8 & 2.8 & 26.1 & -1.1 & 43.4 \\
$4 / 20 / 83$ & 1.7 & -1.7 & & 3.3 & 46.7 \\
$4 / 21 / 83$ & 5.6 & -5.6 & & 7.2 & 54.0 \\
$4 / 22 / 83$ & 4.4 & -4.4 & & 6.1 & 60.1 \\
$4 / 23 / 83$ & 3.3 & -3.3 & & 5.0 & 65.1 \\
$4 / 24 / 83$ & 3.9 & -3.9 & & 5.6 & 70.6 \\
$4 / 25 / 83$ & 8.9 & -8.9 & & 10.6 & 81.2 \\
$4 / 26 / 83$ & 11.7 & -11.7 & & 13.3 & 94.5 \\
$4 / 27 / 83$ & 15.0 & -15.0 & & 16.7 & 111.2 \\
$4 / 28 / 83$ & 7.2 & -7.2 & & 8.9 & 120.1 \\
$4 / 29 / 83$ & 8.9 & -8.9 & & 10.6 & 130.7 \\
$4 / 30 / 83$ & 6.7 & -6.7 & & 8.3 & 139.0 \\
$5 / 1 / 83$ & 3.9 & -3.9 & & 5.6 & 144.6 \\
$5 / 2 / 83$ & 8.9 & -8.9 & & 10.6 & 155.1 \\
$5 / 3 / 83$ & 5.0 & -5.0 & & 6.7 & 161.8 \\
$5 / 4 / 83$ & 3.9 & -3.9 & & 5.6 & 167.3 \\
$5 / 5 / 83$ & 4.9 & -4.4 & & 6.1 & 173.5 \\
$5 / 6 / 83$ & 6.7 & -6.7 & & 8.3 & 181.8 \\
$5 / 7 / 83$ & 7.2 & -7.2 & & 8.9 & $190.7^{\mathrm{j}}$ \\
$5 / 8 / 83$ & 3.9 & -3.9 & & 5.6 & 196.2 \\
$5 / 9 / 83$ & 3.9 & -3.9 & & 5.6 & 201.8 \\
$5 / 10 / 83$ & 7.8 & -7.8 & & 9.4 & 211.3 \\
$5 / 11 / 83$ & 11.1 & -11.1 & & 12.8 & 224.0 \\
$5 / 12 / 83$ & 12.8 & -12.8 & & 14.4 & 238.5 \\
$5 / 13 / 83$ & 14.4 & -14.4 & & 16.1 & 254.6 \\
$5 / 14 / 83$ & 8.9 & -8.9 & & 10.6 & 265.2 \\
$5 / 15 / 83$ & 4.9 & -4.4 & & 6.1 & 271.3 \\
$5 / 16 / 83$ & 3.9 & -3.9 & & 5.6 & 276.8 \\
$5 / 17 / 83$ & 5.0 & -5.0 & & 6.7 & 283.5 \\
$5 / 18 / 83$ & 7.8 & -7.8 & & 9.4 & 292.9 \\
$5 / 19 / 83$ & 10.6 & -10.6 & & 12.2 & 305.2 \\
$5 / 20 / 83$ & 11.7 & -11.7 & & 13.3 & 318.5 \\
\hline & & & & \\
5 & & & & & \\
\hline
\end{tabular}

'Early freeze (11/12/1982-11/17/1982, 11/22/1982-11/30/1982).

'Start of freeze (12/4/1982).

Early thaw (2/13/1983-2/23/1983, 2/27/1983-3/8/1983).

${ }^{\mathrm{d}}$ Freezing index $=617.2^{\circ} \mathrm{C}$-days.

'Start of thaw (3/30/1983).

"'Should level" restriction $T I=16.7^{\circ} \mathrm{C}$-days $>13.9^{\circ} \mathrm{C}$-days (4/3/1983).

s" "Must level" restriction $T I=27.8^{\circ} \mathrm{C}$-days $=27.8^{\circ} \mathrm{C}$-days $(4 / 6 / 1983)$.

${ }^{b}$ Late freeze (4/15/1983-4/19/1983).

${ }^{1}$ End of thaw $164=4.154+0.259(617.2){ }^{\circ} \mathrm{C}$-days $(5 / 4 / 1983)$.

${ }^{j}$ End of thaw $185.2=0.3 \times(617.2){ }^{\circ} \mathrm{C}$-days $(5 / 7 / 1983)$.

Data from frost tubes were analyzed assuming "thick" pavement sections, as defined in the FHwA method. Thaw reaching $102 \mathrm{~mm}$ below the bottom of the subbase ("must level" load restriction) was used as the criterion to determine the start of thaw. The cross sections shown in Fig. 6 were used in the analysis. A 102-mm-thick surface and 152-mm-thick subbase were as- 


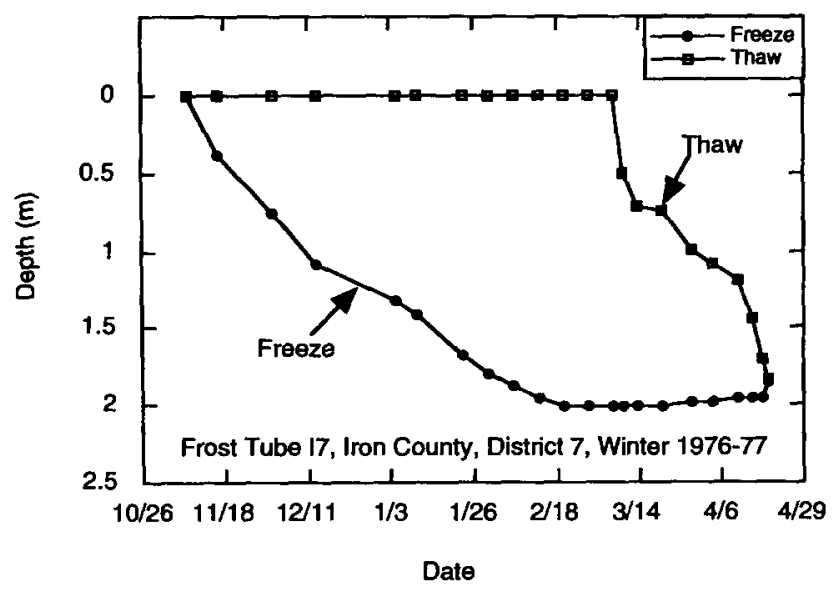

FIG. 7. Example of Frost-Tube Data
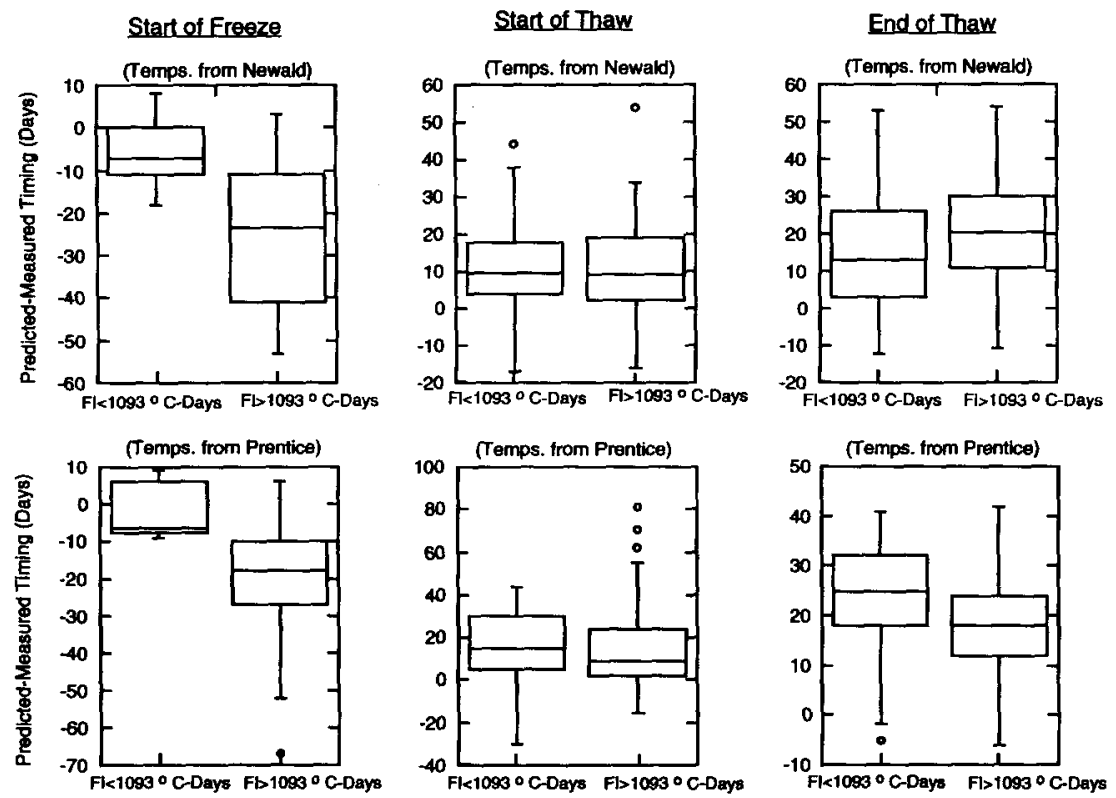

FIG. 8. Difference in Dates for Predicted and Measured Phase Changes versus Freezing Index

sumed for locations where the thicknesses of the pavement sections were not known. A similar assumption was used for the analyses performed with the FHwA method.

In the northern parts of Wisconsin, there are a number of years when the freezing index is greater than $1,093^{\circ} \mathrm{C}$-days, which is the largest freezing index used when developing the FHwA method. To determine whether this might affect the results, a comparison was made between the difference be- 


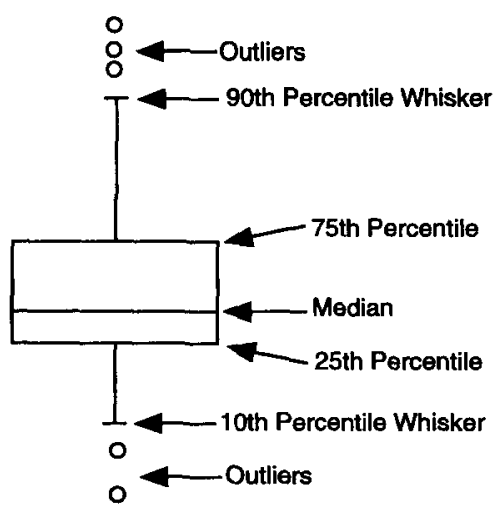

FIG. 9. Schematic of Box Plot

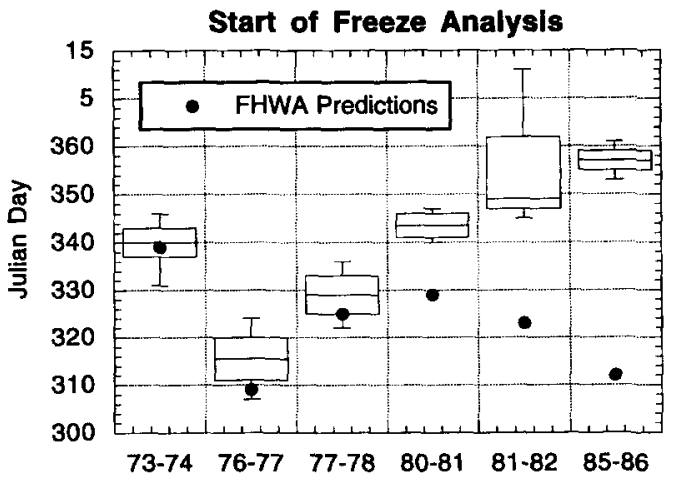

FIG. 10. Comparison between FHwA Predictions and Frost-Tube Data for Start of Freeze

tween the predicted and measured dates of freeze, start of thaw, and end of thaw for data sets where the $F I$ is less than and greater than $1,093^{\circ} \mathrm{C}$-days. This comparison is shown in Fig. 8 in the form of box plots. A box plot (Fig. 9) is a graphical means to statistically describe data. The center line in the "box" represents the median, the outer edges represent the 25 th and 75th percentiles, and the "whiskers" represent the 10th and 90th percentiles (Fig. 9). Circles outside the whiskers represent outlier data, which are defined as data falling outside the 10th and 90th percentiles.

Fig. 8 shows that there are no differences between the predicted and measured dates for thaw. Thus, the FHwA method predicts the start of thaw for locations having $F I$ greater than $1,093^{\circ} \mathrm{C}$-days as accurately as it predicts the start of thaw for $F I$ less than $1,093^{\circ} \mathrm{C}$-days. In contrast, for the start of freeze there is a distinct difference between the predicted and measured dates for those sites having freezing indices less than and greater than $1,093^{\circ} \mathrm{C}$-days.

For each frost-tube location, the start of freeze, start of thaw, and end of thaw were determined using the FHwA method and using the frost tube data. The data in Figs. 10-12 are from frost tubes in District 7 with weather data from the Newald station. Similar results could been shown for any other location. In Figs. 10-12, the solid symbols (circles and triangles) represent 


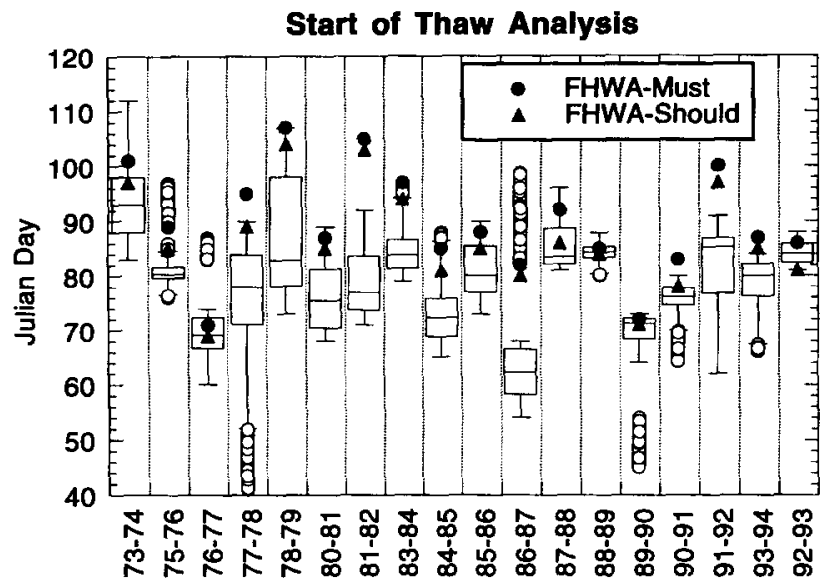

FIG. 11. Comparison between FHwA Predictions and Frost-Tube Data for Start of Thaw

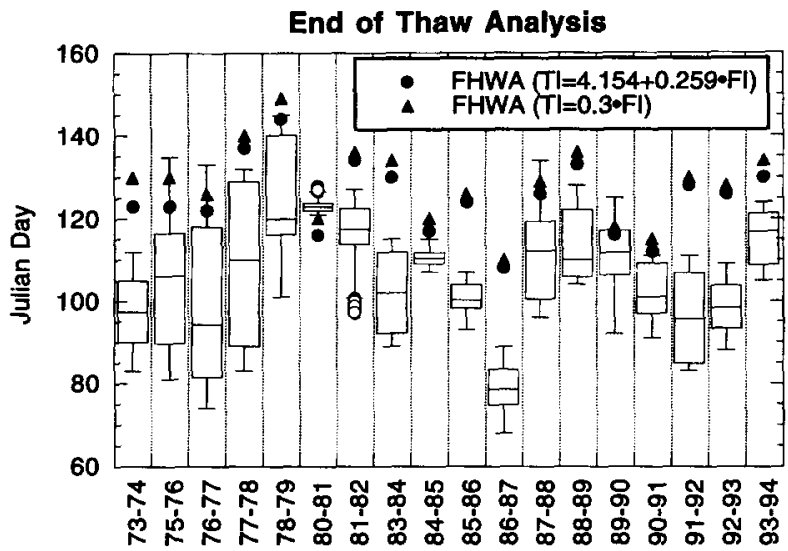

FIG. 12. Comparison between FHwA Predictions and Frost-Tube Data for End of Thaw

the date for the start of freeze (Fig. 10), start of thaw (Fig. 11), and end of thaw (Fig. 12) as predicted using the FHwA method, whereas the box plots (including the open circles as outliers) represent data from the frost tubes.

\section{Start of Freeze}

The data presented in Fig. 10 indicate that the start of freeze is usually predicted earlier using the FHwA method. For example, in District 7 for the winter of 1981-82, the predicted start of freeze is Julian Day 323, 1981, using the FHwA method (Fig. 10). However, one of the frost tubes in this area indicates that the ground froze between Julian Day 348, 1981, and Julian Day 11, 1982; and the second frost tube indicates the start of freeze between Julian Day 345 and Julian Day 349, 1981. This is significant because the ground is deemed frozen before freezing actually starts; i.e., the prediction is unconservative relative to the potential for roadway damage by permitting 
heavier loads on the roads during frozen periods. In addition, early freeze periods exist in most of the data presented in Fig. 10 (Yesiller et al. 1995). Because of the early freeze, the predicted start of the freezing season can be significantly earlier than the actual start of the freezing season. The writers note, however, that the FHwA method was developed primarily for predicting thawing. Thus, using the method to predict freezing is not necessarily appropriate. If used in this fashion, however, predictions made with the FHwA method are unconservative.

\section{Start of Thaw}

The data in Fig. 11 indicate that the start of thaw predicted using the FHwA method occurs later than the actual thaw, on average. For example, in the winter of 1981-82, the start of thaw is predicted as Julian Day 105, 1982 ("must level" load restriction). However, the frost tubes indicate that the ground started thawing around Julian Day 75, 1982. Further examination of the full data set shows that the FHwA method predicts the start of thaw as much as one to two months later than the start of thaw predicted by frost tubes. This makes the FHwA method unconservative, because the ground is deemed frozen (and thus larger load limits are allowed) after it actually starts thawing.

\section{End of Thaw}

The data in Fig. 12 indicate that the end of thaw is also usually predicted later using the FHwA method. For example, in the winter of 1983-84, the end of thaw is predicted as Julian Day 133, 1984, using the FHwA method; however, the frost tubes indicate that the ground was completely thawed around Julian Day 102. Again, this difference, which can be up to a month, is significant. In this case, however, the FHwA method is conservative, because, according to the FHwA method, critical conditions exist even though the frost tubes indicate complete thaw has occurred.

\section{CASE HISTORY}

Since 1991 the Maintenance Division in District 7 of the Wisconsin Department of Transportation (WisDOT) has been using the FHwA method to determine the timing and duration of spring highway load restrictions. The WisDOT personnel use air temperatures from Nicolet College Weather Station located in Rhinelander, Wis. (Fig. 5). Results of the WisDOT analysis for the winter of 1992-93 are presented in Table 2. The writers note that predictions made using the FHwA method for District 7 that are presented in Figs. 10-12 were made using air temperatures from a closer weather station (Newald), which is located in the same district as the Nicolet station. Thus, differences exist between the predictions shown in Figs. 10-12, and those made by WisDOT.

The predicted and measured conditions and the WisDOT postings for the winter of 1992-93 are shown in Table 3. The start of freeze, start of thaw, and end of thaw were predicted using the FHwA method and air temperatures from the Nicolet station, as well as weather stations at Newald and Prentice stations. The data from the frost tubes indicate that the start of thaw occurs earlier than or at a similar time as the time predicted using the FHwA method (Table 3). The WisDOT Maintenance Division initially posted load restrictions on March 3, 1993, based on the FHwA predictions. However, none of the frost tubes in District 7 indicated thawing in the ground in early March. 
TABLE 2. Timing and Duration of Load Restrictions Determined by District 7 WisDOT Maintenance Division for Winter 1992-1993

\begin{tabular}{|c|c|c|c|}
\hline $\begin{array}{c}\text { Date } \\
\text { (1) }\end{array}$ & $\begin{array}{c}\text { Average } \\
\text { temperature } \\
\left({ }^{\circ} \mathrm{C}\right) \\
(2)\end{array}$ & $\begin{array}{c}F I \\
\text { ( }{ }^{\circ} \mathrm{C} \text {-days) } \\
\text { (3) }\end{array}$ & $\begin{array}{c}T I \\
\left({ }^{\circ} \mathrm{C}-\text { days }\right) \\
\text { (4) }\end{array}$ \\
\hline $\begin{array}{l}3 / 1 / 93 \\
3 / 2 / 93 \\
3 / 3 / 93 \\
3 / 4 / 93 \\
3 / 5 / 93 \\
3 / 6 / 93 \\
3 / 7 / 93 \\
3 / 8 / 93 \\
3 / 9 / 93 \\
3 / 10 / 93 \\
3 / 11 / 93 \\
3 / 12 / 93 \\
3 / 13 / 93 \\
3 / 14 / 93 \\
3 / 15 / 93 \\
3 / 16 / 93 \\
3 / 17 / 93 \\
3 / 18 / 93 \\
3 / 19 / 93 \\
3 / 20 / 83 \\
3 / 21 / 93 \\
3 / 22 / 93 \\
3 / 23 / 93 \\
3 / 24 / 93 \\
3 / 25 / 93 \\
3 / 26 / 93 \\
3 / 27 / 93 \\
3 / 28 / 93 \\
3 / 29 / 83 \\
3 / 30 / 83 \\
3 / 31 / 93 \\
4 / 1 / 93 \\
4 / 2 / 93 \\
4 / 3 / 93 \\
4 / 4 / 93 \\
4 / 5 / 93 \\
4 / 6 / 93 \\
4 / 7 / 93 \\
4 / 8 / 93 \\
4 / 9 / 93 \\
4 / 10 / 93 \\
4 / 11 / 93 \\
4 / 12 / 93 \\
4 / 13 / 93 \\
4 / 14 / 93 \\
4 / 15 / 93 \\
4 / 16 / 93 \\
4 / 17 / 93 \\
4 / 18 / 93 \\
4 / 19 / 93 \\
4 / 20 / 93\end{array}$ & $\begin{array}{r}-2.2 \\
3.3 \\
5.0 \\
1.7 \\
0.0 \\
0.0 \\
3.9 \\
-1.1 \\
-1.1 \\
0.0 \\
-4.4 \\
-12.2 \\
-11.1 \\
-15.6 \\
-12.2 \\
-2.2 \\
-11.1 \\
-15.6 \\
-5.6 \\
-1.7 \\
0.0 \\
-2.2 \\
0.0 \\
5.6 \\
7.2 \\
3.3 \\
4.4 \\
7.8 \\
8.9 \\
8.9 \\
10.6 \\
-3.3 \\
-5.0 \\
-2.8 \\
-1.1 \\
2.2 \\
-4.4 \\
1.1 \\
6.7 \\
3.3 \\
5.6 \\
0.0 \\
2.2 \\
3.3 \\
0.0 \\
0.0 \\
-1.1 \\
-1.1 \\
7.8 \\
2.8 \\
4.4\end{array}$ & $\begin{array}{l}713.9 \\
710.6 \\
705.6 \\
703.9 \\
703.9 \\
703.9 \\
700.0 \\
701.1 \\
702.2 \\
702.2 \\
706.7 \\
718.9 \\
730.0 \\
745.6 \\
757.8 \\
760.0 \\
771.1 \\
786.7 \\
792.2 \\
793.9 \\
793.9 \\
796.1 \\
796.1 \\
790.6 \\
783.3 \\
780.0\end{array}$ & $\begin{array}{r}1.7 \\
1.1 \\
2.8 \\
10.0 \\
18.9 \\
23.9 \\
30.0^{4} \\
39.4 \\
50.0 \\
60.6 \\
72.8 \\
71.1 \\
67.8 \\
66.7 \\
67.2 \\
71.1 \\
68.3 \\
71.1 \\
79.4 \\
84.4 \\
91.7 \\
93.3 \\
97.2 \\
102.2 \\
103.9 \\
105.6 \\
106.1 \\
106.7 \\
116.1 \\
120.6 \\
126.7\end{array}$ \\
\hline
\end{tabular}


TABLE 2 (Continued)

\begin{tabular}{c|c|c|c}
\hline$(1)$ & $(2)$ & (3) & $(4)$ \\
\hline $4 / 21 / 93$ & 1.1 & & 129.4 \\
$4 / 22 / 93$ & 3.3 & & 134.4 \\
$4 / 23 / 93$ & 6.1 & & 142.2 \\
$4 / 24 / 93$ & 9.4 & & 153.3 \\
$4 / 25 / 93$ & 2.8 & & 157.8 \\
$4 / 26 / 93$ & 1.7 & & 161.1 \\
$4 / 27 / 93$ & 5.6 & & 188.3 \\
$4 / 28 / 93$ & 15.6 & & 198.6 \\
$4 / 29 / 93$ & 11.7 & & 210.0 \\
$4 / 30 / 93$ & 9.4 & & 220.6 \\
$5 / 1 / 93$ & 8.9 & & 230.6 \\
$5 / 2 / 93$ & 8.3 & & 240.0 \\
$5 / 3 / 93$ & 7.8 & & 253.9 \\
$5 / 4 / 93$ & 12.2 & & \\
\hline
\end{tabular}

"Freezing index continued from previous months.

'Tnitial posting of load restrictions.

${ }^{\circ}$ Removal of load restrictions.

dSecond posting of load restrictions.

Removal of load restrictions.

TABLE 3. Data for District 7 (FHwA Guidelines and Frost Tubes) for Winter 1992-93

\begin{tabular}{|c|c|c|c|}
\hline $\begin{array}{l}\text { Method } \\
\text { (1) }\end{array}$ & $\begin{array}{c}\text { Start of freeze } \\
\text { (2) }\end{array}$ & $\begin{array}{c}\text { Start of thaw } \\
\text { (3) }\end{array}$ & $\begin{array}{l}\text { End of thaw } \\
\text { (4) }\end{array}$ \\
\hline $\begin{array}{l}\text { FHwA Newald sta- } \\
\text { tion }\left(F I=980.6^{\circ} \mathrm{C}-\right. \\
\text { days })\end{array}$ & $\begin{array}{l}11 / 22 / 92 \text { or } 11 / 5- \\
11 / 8(F I=24.4)- \\
\text { early freeze } \\
11 / 12-11 / 19(F I= \\
40.6)- \text { early } \\
\text { freeze }\end{array}$ & $\begin{array}{l}3 / 28 / 93 \text { — "must" } \\
\text { level } \\
3 / 26 / 93 \text { — "should" } \\
\text { level }\end{array}$ & $\begin{array}{l}\text { 5/6/93-Eq. (3) } \\
\text { 5/8/93 -Eq. (4) }\end{array}$ \\
\hline $\begin{array}{l}\text { FHwA Prentice St. } \\
\left(F I=1103.9^{\circ} \mathrm{C}-\right. \\
\text { days })\end{array}$ & $\begin{array}{l}11 / 13 / 92 \text { or } 11 / 5- \\
11 / 9(F I=21.1)- \\
\text { early freeze }\end{array}$ & $\begin{array}{l}3 / 29 / 93 \text { - "must" } \\
\text { level } \\
3 / 26 / 93 \text { - "should" } \\
\text { level }\end{array}$ & $\begin{array}{l}5 / 8 / 93-\text { Eq. (3) } \\
5 / 10 / 93-\mathrm{Eq} .(4) \\
4 / 1-4 / 4(F I=15) \\
\text { late freeze }\end{array}$ \\
\hline Frost tube & Not available & $\begin{array}{l}3 / 22 / 93-3 / 26 / 93- \\
\text { Tube } 2 \\
3 / 22 / 93-3 / 29 / 93- \\
\text { Tubes } 3-6 \\
3 / 8 / 93-3 / 25 / 93- \\
\text { Tubes } 7 \& 9 \\
3 / 29 / 93-4 / 2 / 93- \\
\text { Tube } 8\end{array}$ & $\begin{array}{l}4 / 12 / 93-4 / 19 / 93- \\
\text { Tube } 4 \\
4 / 5 / 93-4 / 12 / 93- \\
\text { Tube } 5 \\
3 / 29 / 93-4 / 5 / 93- \\
\text { Tube } 6 \\
3 / 31 / 93-4 / 20 / 93- \\
\text { Tube } 10\end{array}$ \\
\hline $\begin{array}{l}\text { FHwA WisDOT } \\
\text { Data-Nicolet St. } \\
\left(F I=748.3^{\circ} \mathrm{C}-\right. \\
\text { days })\end{array}$ & $11 / 13 / 92$ & $\begin{array}{l}3 / 25 / 93-“ \text { - should" } \\
\text { level } \\
3 / 27 / 93 \text { - WisDOT } \\
\text { posting } \\
3 / 2-3 / 10(T I= \\
26.7) \text { - early thaw }\end{array}$ & $\begin{array}{l}\text { 4/29/93-Eq. (3) } \\
\text { 5/2/93-Eq. (4), } \\
\text { WisDOT posting } \\
\text { removed }\end{array}$ \\
\hline
\end{tabular}


Because of subsequent cold temperatures, this initial posting was removed on March 15, 1993. The load restrictions were posted again on March 27, 1993 ("must level" restrictions). This second posting date was close to the time interval for start of thaw indicated by the frost tubes in District 7 (Table 3).

The end of thaw was predicted later using the FHwA method than indicated by frost tubes. Load restrictions were removed on May 2, 1993, by the WisDOT Maintenance Division. However, the frost tubes indicated that the end of thaw occurred one week to one month earlier than predicted by the FHwA method (Table 3). Thus, the load restrictions remained in place one month after complete thaw had occurred.

\section{SUMMARY AND CONCLUSIONS}

In this study, dates for the start of freezing, start of thawing, and end of thawing were predicted using the FHwA method and directly determined using frost-tube data. The predicted and directly determined dates were then compared. Based on this comparison, the following conclusions are drawn:

1. The FHwA method was developed for locations that have FIs between 204 and $1,093^{\circ} \mathrm{C}$-days and mean annual air temperatures between 4.4 and $10^{\circ} \mathrm{C}$. However, it was found that predictions of the start and end of thaw made with the FHwA method are equally accurate for locations where the $F I$ is less than and greater than $1,093^{\circ} \mathrm{C}$-days. In the analysis, $F / s$ as large as $1,550^{\circ} \mathrm{C}$-days were encountered. However, the prediction of start of freeze was significantly less accurate for locations having $F I$ greater than $1,093^{\circ} \mathrm{C}$-days.

2. In the FHwA method, the criteria for the start of the freezing season and the start of the thawing season are not well defined. It is possible to choose the correct dates for the start of freeze or thaw when historical data are analyzed (e.g., Table 2). However, when real-time data are analyzed, it is highly probable that an "early freeze" will be interpreted as the start of the freezing season (or an early thaw as the start of the thawing season).

3. Differences exist between predicted (FHwA method) and measured (frost tubes) freeze and thaw conditions. The start of freeze is usually predicted (using the FHwA method) earlier than is indicated by frost tubes. In most cases, the start of thaw is predicted later using the FHwA method than indicated by frost tubes. In both cases, the soil is deemed frozen while it actually is thawed. Therefore, the FHwA method is unconservative (relative to the potential for roadway damage) for predicting the start of freeze and thaw. The writers note, however, that the FHwA method was developed primarily to predict thawing. In contrast, the FHwA method is conservative when used to predict the end of thaw. That is, the end of thaw indicated by the frost tubes is earlier than predicted by the FHwA method. Consequently, the soil is considered to be thawing, whereas it actually has completely thawed.

These findings indicate that the FHwA method should be used with caution when predicting the start of thawing or the start of freezing. Direct methods of assessing the start of thaw or start of freezing, such as frost-tube measurements, unfrozen water contents, and/or deflection surveys, are likely to be more reliable. Furthermore, it is less likely that unconservative predictions 
of the condition of the base and subgrade will be made when direct measurements are used.

\section{ACKNOWLEDGMENTS}

This study was sponsored by the Wisconsin Department of Transportation (WisDOT). Terry Rutkowski and Robert Schmiedlin of WisDOT are the project monitor and director of research, respectively. Assistance provided by James Voborsky and Thomas Martinelli of WisDOT is also gratefully acknowledged. This paper has not been reviewed by WisDOT and no endorsement should be assumed.

\section{APPENDIX. REFERENCES}

Barcomb, J. (1989). "Use of thermistors for spring road management." Transp. Res. Rec. 1252, Trans. Res. Board, Nat. Res. Council, Washington, D.C., 12-20.

Goering, D., and Zarling, J. (1985). TDHC finite element program user's manual. Univ. of Alaska, Fairbanks, Alaska.

Mahoney, J. P., Lary, J A., Sharma, J., and Jackson, N. C. (1985). "Investigation of seasonal load restrictions in Washington State." Transp. Res. Rec. 1043, Transp. Res. Board, Nat. Res. Council, Washington, D.C., 58-67.

Mahoney, J. P., Rutherford, M. S., and Hicks, R. G. (1987). "Guidelines for spring highway use restrictions." Rep., FHWA-TS-87-209, Federal Hwy. Admin., McLean, Va.

Martinelli, T. J. (1977). "The use of frost depth indicators in Wisconsin highways." Summary Rep., Res. Unit, Mat. Section, Div. of Hwy., Wisconsin Dept. of Transp., Madison, Wis.

McBane, J. A., and Hanek, G. (1986). "Determination of the critical thaw-weakened period in asphalt pavement structures." Transp. Res. Rec. 1089, Transp. Res. Board, Nat. Res. Council, Washington, D.C., 138-146.

Rutherford, M. S., and Mahoney, J. P. (1986). "A thermal analysis of pavement thawing." Proc., Fourth Int. Conf. on Cold Regions Engrg., ASCE, New York, N.Y.

Rwebangira, T., Rutherford, M. S., Mahoney, J. P., and Hicks, R. G. (1987). "Development of spring load restrictions for local roads." Transp. Res. Rec. 1128, Transp. Res. Board, Nat. Res. Council, Washington, D.C., 42-52.

Yesiller, N., Benson, C. H., and Bosscher, P. J. (1995). "Method development for determining the effect of thermal cycles and moisture conditions on pavement structure." Interim Rep., WisDOT, Wisconsin Dept. of Transp., Madison, Wis. 